Medical University, Xi'an, China; ${ }^{2}$ Rheumazentrum Ruhrgebiet Herne, RuhrUniversity Bochum, Herne, Germany, Herne, Germany

Background: Hip joint lesion are the main cause of disability in patients with Ankylosing Spondylitis(AS) in western China. Seriously affect the quality of life of patients. The early clinical characteristics of hip joint disease are not typical, the disease is insidious, and the radiological diagnosis is delayed.The main prevention is early screening and early diagnosis.

Objectives: This study attempted to find out the main characteristics and related factors in different groups of AS combine with hip joint lesion in western China.

Methods: A-First evaluation: How many patients have 1) active SIJ changes on MRI. 2) chronic SIJ changes (each for erosion, clerosis, ankylosis, or any of those) on MRI. 3) a combination of active changes and chronic changes (each for erosion, sclerosis, ankylosis, or any of those) on MRI. 4) active hip changes on MRI. 5) chonic hip changes (erosion, effusion any of those) on MRI. 6) a combination of active changes and chronic hanges (erosion, effusion any of those) on MRI. B-Then, combination SIJ / hip. 7) active SIJ changes on MRI and in parallel active hip changes on MRI. 8) chronic (see above) SIJ changes on MRI and in parallel active hip changes on MRI. 9) chronic (see above) SIJ changes on MRI and in parallel chronic (see above) hip changes on MRI. 10) chronic (see above) SIJ changes on MRI and in parallel any (active or chronic) hip changes on MRI. C-Then, characterization of these groups with non-imaging findings. Characteristics of groups 7-10 above, for age, sex, Disease duration, Hip pain, Joint pain, enthesitis, Diarrhea, uveitis, ASDAS-CRP, BASDAI, BASFI, BASMI, Pat. Global, CRP, ESR, Harris Score, HLA-B27.

Results: Retrospective analysis total $558 \mathrm{SpA}$ patients (mean age 29, mean duration 5 years). 1) HIP-Active+Chronic group $(\mathrm{N}=288, A S=151)$ vs $S I J+H I P-A c t i v e$ group $(N=241, A S=138)$ : hip pain $(p<0.0001)$, diarrhea $(p<0.0001)$, joint pain $(p<0.0001)$ and BASFI $(p<0.05) ; 2)$ HIP-Active+Chronic $(\mathrm{N}=117, \quad A S=58)$ vs $\mathrm{SIJ}$-Chronic+HIP-Active group $(\mathrm{N}=214$, $A S=134)$ : hip pain $(p<0.0001)$, joint pain $(p<0.0001)$, enthesitis $(p<0.0001)$, ASDAS-CRP $(p<0.05)$ and ESR $(p<0.05)$; 3) SIJ-Active+Chronic group $(\mathrm{N}=204, A S=125)$ vs SIJ-Chronic+HIP-Active group $(\mathrm{N}=214, A S=134)$ : hip pain $(p<0.0001)$, joint pain $(p<0.0001)$; 4$)$ SIJ-Active+Chronic group $(\mathrm{N}=204, A S=125)$ vs $\mathrm{SIJ}+\mathrm{HIP}-$ Chronic group $(\mathrm{N}=72, A S=40)$ :hip pain $(p<0.0001)$, Pat. Global $(p<0.05) ; 5)$ SIJ+HIP-Active group $(N=241, A S=138)$ vs SIJ-Chronic+HIP-Active group ( $\mathrm{N}=214$, $\mathrm{AS}=134)$ : HLA-B27 positive (Chisquare, df, 24.98, 4) $(p<0.0001) ; 6)$ SIJ+HIP-Chronic group $(N=72, A S=40)$ vs SIJ-Chronic+HIP-Active/Chronic group $(\mathrm{N}=228, A S=144)$ : Pat. Global $(p<0.05)$, ESR $(p<0.05)$.

Conclusion: Hip joint lesion are closely related to sacroiliac joint lesion and HLA-B27 positive in AS. Hip pain is the main clinical manifestation of hip joint lesion in AS. Hip joint lesion may lead to function declines, disease activity in AS.

References:

[1] Vander C B, Munoz-Gomariz E, Font P, et al. Hip involvement in ankylosing spondylitis:epidemiology and risk factors associated with hip replacement surgery[J]. Rheumatology (Oxford), 2010,49(1):73-81.

[2] Sieper J, Rudwaleit M, Baraliakos X, et al. The Assessment of SpondyloArthritis international Society (ASAS) handbook: a guide to assess spondyloarthritis[J]. Ann Rheum Dis, 2009,68 Suppl 2:i1-i44.

[3] Ward M M, Deodhar A, Akl E A, et al. American College of Rheumatology/ Spondylitis Association of America/Spondyloarthritis Research and Treatment Network 2015 Recommendations for the Treatment of Ankylosing Spondylitis and Nonradiographic Axial Spondyloarthritis[J]. Arthritis Rheumatol, 2016,68(2):282-298.

Disclosure of Interests: Qing Han: None declared, Zhaohui Zheng: None declared, Kui Zhang: None declared, Zheng Yu: None declared, Fengfan Yang: None declared, Qiang Liang: None declared, Ping Zhu: None declared, Xenofon Baraliakos Grant/research support from: Grant/research support from: AbbVie, BMS, Celgene, Chugai, Merck, Novartis, Pfizer, UCB and Werfen, Consultant of: AbbVie, BMS, Celgene, Chugai, Merck, Novartis, Pfizer, UCB and Werfen, Speakers bureau: AbbVie, BMS, Celgene, Chugai, Merck, Novartis, Pfizer, UCB and Werfen

DOI: 10.1136/annrheumdis-2020-eular.3707

\section{AB0692 CLINICAL SIGNIFICANCE OF LIPID PROFILES IN PATIENTS WITH AXIAL SPONDYLOARTHRITIS}

Y. Huang ${ }^{1}$, M. Liu' ${ }^{1}$, Q. Huang ${ }^{1}$, T. W. Li ${ }^{1} .{ }^{1}$ Guangdong Second Provincial General Hospital, Guangzhou, China

Background: Axial spondyloarthritis (axSpA) is a chronic inflammatory disease of the sacroiliac joints and spine. Lipid profiles, including total cholesterol(TC), high-density lipoprotein cholesterol(HDL-c), low-density lipoprotein cholesterol (LDL-c), TC/HDL-c, triglycerides(TG), have been reported to be changed regularly in axSpA patients. However, the clinical significance of lipid profiles in axSpA patients is controversial.

Objectives: The study aims to determine the clinical significance of TC, HDL-C LDL-c, TC/HDL-c, TG for axSpA patients.

Methods: A total of 208 axSpA patients and 113 healthy subjects were enrolled in the study retrospectively. TC, HDL-c, LDL-c, TC/HDL-c, TG, C-reactive protein (CRP), erythrocyte sedimentation rate (ESR), Bath Ankylosing Spondylitis Disease Activity Index(BASDAI) were collected. AxSpA patients were divided into remission axSpA group(BASDAI $<4$ $n=123$ ) and active axSpA group(BASDAI $\geq 4, n=85)$. Relationships between the parameters were assessed by the Sperman's correlations analysis. Receiver operation characteristic (ROC) curves were used to discriminate axSpA patients from healthy subjects and active axSpA group from remission axSpA group.

Results: TC, HDL-c, and TG in axSpA group were lower than those of control group, while TC/HDL-c was higher $(P<0.05)$. ROC curve results showed that the AUC value of HDL-c for axSpA was 0.790 (CI95\%: $0.740-0.839$ ), yielding a highest AUC value. The optimal cutoff value of HDL-c for axSpA was 1.095 with the Youden index of 0.496 , sensitivity of $65.5 \%$ and specificity of $84.1 \%$. HDL-c was negatively correlated with BASDAI ( $r=-0.159, P=0.022)$. TC/HDL-C was positively correlated with BASDAI $(r=0.183, P=0.008)$. Besides, TC/HDL-c, CRP, ESR in active axSpA group were higher than those of remission axSpA group, while HDL-c was lower $(P<0.05)$. ROC curve results showed that the AUC value of TC/HDL-c and CRP for active axSpA group were 0.621 (CI95\%: 0.543-0.700) and 0.634 (CI95\%: 0.556-0.712), yielding a higher AUC value than other parameters. The optimal cutoff value of TC/HDL-c for active axSpA group was 4.429 , with the Youden index of 0.201 , sensitivity of $40.2 \%$ and specificity of $79.9 \%$.

Conclusion: HDL-c was decreased in axSpA patients with a highest diag nostic value, compared with healthy control. TC/HDL-c was elevated in active axSpA patients, showing a significant correlation to the disease activity of $\operatorname{axSpA}$
A

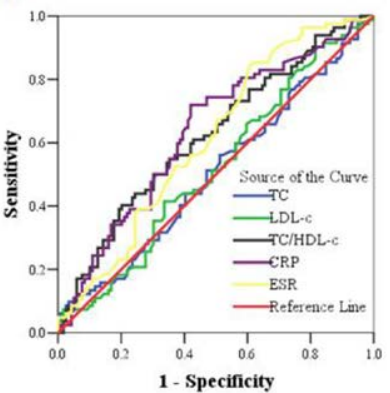

$\mathbf{B}$

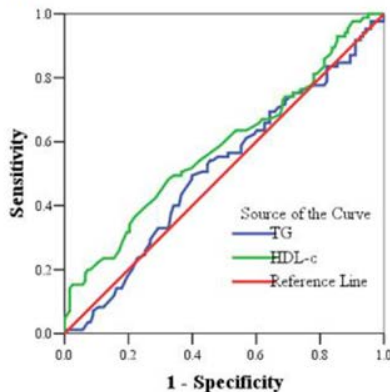

Figure.1 ROC curves was used to discriminate active axSpA group from remission axSpA group.

\section{References:}

[1] Gluszko P, Bonek K, Rupinski R, et al. LIPID PROFILE AND ACTIVE SYSTEMIC INFLAMMATION MAY DIFFERENTLY AFFECT THE PATHOMECHANISM OF CARDIOVASCULAR DISORDERS IN ANKYLOSING SPONDYLITIS (AS) AND IN PSORIATIC ARTHRITIS (PSA)[J]. ANNALS OF THE RHEUMATIC DISEASES. 2016: 1146.

Acknowledgments: This study was supported by Science and Technology Project of Guangzhou Haizhu District (Haike Business Infox 2018-89).

Disclosure of Interests: None declared

DOI: 10.1136/annrheumdis-2020-eular.5988

\begin{tabular}{l|l}
\hline AB0693 & TIM-3-EXPRESSING NEUTROPHILS AS A \\
NOVEL INDICATOR TO ASSESS DISEASE \\
ACTIVITY AND SEVERITY IN ANKYLOSING \\
SPONDYLITIS
\end{tabular}

X. Huang ${ }^{1}$, T. Li ${ }^{1}$, J. Chen ${ }^{1}$, Y. Wang ${ }^{1}$, S. Chen ${ }^{1}$, W. Deng ${ }^{1}$, Q. Huang ${ }^{1}$ ${ }^{1}$ Guangdong Second Provincial General Hospital, Guangzhou, China

Background: Ankylosing spondylitis (AS) is a type of chronic inflammatory disease that compromises the axial skeleton and sacroiliac joints. Many studies have shown that neutrophils play an important roles in the inflammatory process of AS. However, the immunomodulatory roles and mechanisms of neutrophils in AS are poorly understood. T-cell immunoglobulin and mucin domain-containing protein 